\title{
Customized Visualizations of Urban Infill Development Scenarios for Local Stakeholders
}

\author{
Juho-Pekka Virtanen ${ }^{1,2 *}$, Tuulia Puustinen', Kyösti Pennanen³, Matti T. Vaaja1, \\ Matti Kurkela1, Kauko Viitanen', Hannu Hyyppä1,2, Petri Rönnholm \\ ${ }^{1}$ Department of Real Estate, Planning and Geoinformatics, Aalto University, Espoo, Finland \\ ${ }^{2}$ Helsinki Metropolia University of Applied Sciences, Construction and Real Estate Hubic, Helsinki, Finland \\ ${ }^{3}$ VTT Technical Research Centre of Finland, Espoo, Finland \\ Email: *juho-pekka.virtanen@aalto.fi, tuulia.puustinen@aalto.fi, kyosti.pennanen@vtt.fi, matti.t.vaaja@aalto.fi, \\ matti.kurkela@aalto.fi, kauko.viitanen@aalto.fi, hannu.hyyppa@aalto.fi, petri.ronnholm@aalto.fi
}

Received 25 March 2015; accepted 31 May 2015; published 3 June 2015

Copyright (C) 2015 by authors and Scientific Research Publishing Inc.

This work is licensed under the Creative Commons Attribution International License (CC BY).

http://creativecommons.org/licenses/by/4.0/

(c) (i) Open Access

\begin{abstract}
Infill development has been seen as one of the solutions to urban challenges. However, it changes the dynamics and visual appearance of the neighborhood. As infill development usually requires the acceptance of local stakeholders, their perceptions of the resulting intensified housing have a significant role. In this study, customized visualizations illustrating scenarios of infill development were made from the perspective of individual apartments in neighboring residential building. The usefulness of customized visualizations for local stakeholders was studied in the Tammela test area. A 3D virtual model of the existing environment was created. Models depicting the alternative infill buildings were added to the 3D model, which was used to create customized visualizations. These visualizations were utilized in the interviews of local stakeholders. The findings indicate that the customized visualizations help stakeholders conceptualize the impact, and plan and manage the infill development. Visualizations can also be seen as a tool for a resident-driven approach to intensifying housing.
\end{abstract}

\section{Keywords}

3D Model, Resident-Driven Infill Development, Visualization, Interviews of Stakeholders, Laser Scanning

\section{Introduction}

The intensification of urban areas in its many forms—such as compact city development [1], transit oriented *Corresponding author.

How to cite this paper: Virtanen, J.-P., Puustinen, T., Pennanen, K., Vaaja, M.T., Kurkela, M., Viitanen, K., Hyyppä, H. and Rönnholm, P. (2015) Customized Visualizations of Urban Infill Development Scenarios for Local Stakeholders. Journal of Building Construction and Planning Research, 3, 68-81. http://dx.doi.org/10.4236/jbcpr.2015.32008 
development [2] or the residential infill of suburbs [3] —has been seen as one of the solutions to urban challenges worldwide. These challenges include urban sprawl, continuous urbanization, demands for increased ecoefficiency [4], and the decline of suburbs [5]. Additionally, for municipalities, there can be many financial gains in relation to the intensification, such as savings on the infrastructure and service costs [6] and the expansion of the city's tax base [7]. The housing intensification policy is a timely, politically and strategically significant topic in growing urban areas globally [8].

Urban infill projects change both the dynamics and visual appearance of their neighboring area. Local stakeholders' opinions concerning infill development depend on their perception of how the neighborhood would change. In the relevant literature, not-in-my-backyard (NIMBY) outlooks [9] [10] are linked to, e.g., traffic arrangements in the area [9], the loss of recreational areas, such as parks [11], the loss of parking space [12], the loss of open space and privacy, and the loss of neighborhood character [10].

One way to reduce the local stakeholders' concerns about the infill development is to integrate the stakeholders in the planning process. Von Haaren, Warren-Kretzschmar, Milos, and Werthmann reviewed different design approaches to landscape planning and emphasized the need to include local stakeholders [13]. This was considered to make landscape scale decisions understandable and visible in a personal context. Tress and Tress also called for engaging the local stakeholders in the planning process [14]. This could reduce the distrust that laymen stakeholders may have towards the planning authorities, and top-down planning in general. The resulting increase of trust between stakeholders could ease the planning process.

Visualizations hold the potential to help conceptualize the effects of infill development for local stakeholders and help engage them in the planning process. A study by Lewis and Sheppard on visualizing the effects of forest management plans for members of indigenous communities in Canada showed that 3D visualizations were considered far more explanatory than traditional presentation media, e.g., maps [15]. Wagner et al. developed the so-called MR-Tent to engage different professional and local laymen stakeholders to urban planning processes with interactive visualizations [16]. The study shows that this could be fruitful in developing a general strategy for the site. Tress and Tress utilized visualizations of scenarios for participatory landscape planning in Denmark and reported that visualizations possess great communication potential for use in the planning process [14]. However, they called for more dynamic tools than static images. Priess and Hauck developed visual scenario maps to illustrate future land use and presented them to several regional stakeholders [17]. This approach produced a variety of different viewpoints that could be utilized in further planning. In the study of future urban planning, Oksman, Väätänen and Ylikauppila examined different stakeholders' views on three different visualization techniques: interactive public screens, multiuser design tables, and a web-based service with panoramic views [18]. Both professional and laymen stakeholders found several benefits in these techniques for future urban planning, especially in projects linked to the local stakeholders' neighborhood.

To involve stakeholders, the visualizations should be relevant for them. They should offer the possibility of accurately evaluating and giving feedback on the proposed plan (cf. [16] [18]). When planning the infill development of residential areas, the current residents are the most relevant local stakeholders. They should be able to examine its effects from their own point of view, that of individual apartments. Visualizations are required to illustrate both the existing environment and the design of the infill development project.

In construction, new building projects are commonly visualized by using virtual 3D models of the planned buildings [19]. These can be combined with photographs of the existing environment. If a 3D model of the environment is used, the project can be studied from all possible viewing positions. Thus, by using 3D models of the environment and the infill development project, it is possible to produce visualizations that illustrate the change from the perspective of any individual apartment.

In this study, we create customized visualizations of the infill development project for every individual apartment of a neighboring residential multi-story building by using 3D models of the project and the existing environment. These floor-by-floor visualizations are used together with animations, in indicative interviews of local stakeholders. The aims of this study are to test the feasibility of producing customized visualizations from 3D models, to explore stakeholders' attitudes and perceptions towards them, and finally, to test the utility of these customized visualizations. The findings of the study contribute to the literature on the tools of residentdriven planning, visualization techniques, and housing intensification possibilities.

\section{The Visualization of Construction Projects}

Either static or interactive 3D visualizations can be utilized for public consultation in construction projects. Im- 
ages and plans are considered static visualizations, and applications of virtual environments and gaming technology are considered interactive [20]. In interactive 3D visualizations the users are free to move around and investigate the 3D environments [21]. It is also possible to include other aspects, such as acoustics, in addition to the visual characteristics of the target [22]. In an experiment reported by van Schaik, the participants preferred interactive visualizations over static visualizations, highlighting the possibility of choosing their viewing position [20].

For presenting interactive visualizations, different techniques can be used in addition to regular computer monitors. The scenes can be examined in immersive Cave Automatic Virtual Environments (CAVEs) [23], or using a head-mounted Virtual Reality (VR) display such as the Oculus Rift [24]. Augmented Reality (AR) techniques are another area of technology studied for visualizing construction projects [25]. 3D design models can be presented in AR [26]. Such systems utilize a video stream as a background. 3D models are superimposed on the image plane according to real-time orientation information. The increase in the computational capabilities of handheld devices has created considerable interest in developing AR applications for mobile devices too.

For interactive visualizations, accurate 3D models are required. They can be produced from the existing environment with surveying methodologies. The alternatives are geodetic measurements, photogrammetric techniques, and laser scanning. Modern photogrammetric applications utilize dense image matching algorithms, allowing the automatic creation of 3D point clouds of the scene [27]. Airborne Laser Scanning (ALS) and Terrestrial Laser Scanning (TLS) collect 3D point clouds efficiently and are widely used [28]. In addition, emerging mobile mapping systems can collect laser scanning data quickly from the terrestrial perspective (see e.g., [29]).

\section{Background for the Study: The Target Area and Local Stakeholders}

In Finland, apartments are typically owned in the specialized limited company form known as a housing company. The shareholders do not own any real estate units but the shares they own entitle them to possess their apartments. If on freehold, the housing companies are in the key role-deciding on and initiating the infill development on their plots [30]-[32]. If the municipality permits and if the majority of the shareholders agree, a part of the plot with building rights can be sold for infill development. The revenues can be used, e.g., on major repairs.

A housing company is managed by a board with the assistance of a hired housing manager who acts as the chief executive officer of the company [33]. Typically, the board consists of laymen shareholders living in the property owned by the housing company. Based on a proposition prepared by the board, the major decisions concerning the property, such as a decision regarding an infill development, are made in a general assembly of all the shareholders. Thus, the main local stakeholders in the context of the current study are the chair of the board, the housing manager, and the shareholders of the housing company.

For this study, an individual housing company with infill development potential located in Tammela was selected. Currently, one seven-floor residential building with 32 apartments and a low-rise commercial building are situated on the plot. Tammela is a neighborhood with approximately 6500 residents, located in the center of Tampere, the third biggest municipality in Finland. The city has created a strategic vision for the intensification of the relatively loosely built neighborhood and outlined plans for its infill development on a general level. The aim is to build housing for 4000 new residents [34] [35]. The city's outlines for the infill development are used as a reference for visualizations; a low-rise commercial building is to be demolished and replaced with a multistory residential building.

\section{Materials and Methods}

The empirical part of the study consisted of two components: the creation of customized visualizations, and their use in indicative interviews of local stakeholders. The creation of synthetic views from arbitrary viewing perspectives requires a complete 3D model of an area. As there was no suitable 3D model of Tammela available, several data sources were utilized for 3D model generation. To achieve complete 3D models of the buildings, both terrestrial and airborne data were used. Based on the models, customized visualizations depicting two alternative infill development scenarios were created.

The aim of the interviews was to explore local stakeholders' perceptions of customized visualizations illustrating a small-scale infill development in the proximity of their apartments. It was expected that the findings provide indications of the utility of 3D models as a tool to illustrate different options of infill development for 
decision makers.

\subsection{Data Sets for 3D Models}

TLS data were collected with a Faro Focus 3D laser scanner (Table 1), using a scanning resolution resulting in a point spacing of $6 \mathrm{~mm}$ at the distance of $10 \mathrm{~m}$. Several scans were acquired, their registration being applied by using spherical targets that were placed around the scanner. Finally, the point cloud was colorized by using the internal camera of the scanner.

The National Land Survey of Finland (NLS) provided pre-oriented ALS data (with a point density of 0.5 points per square meter) and orthoimages. In addition, terrestrial photographs were used to texture the model. The ground sample distance of the orthoimages was $0.5 \mathrm{~m}$. Terrestrial images were taken with a Nikon D700 camera and $14-24 \mathrm{~mm} \mathrm{f} / 2.8$ lens. The lens was fixed at $14 \mathrm{~mm}$. The camera was calibrated and lens distortions were removed from images [36]. Fourteen of them were used in texturing the nearby buildings.

\subsection{Creation of the 3D Model of the Environment}

The 3D model of the existing area was produced by integrating the TLS and ALS data. The low point density of ALS data prevented the modeling of small details. However, with this data it was feasible to create a digital terrain model and extract coarse outlines of existing buildings. ALS data was classified to ground, building, and vegetation points with the Axelsson method [37]. After this, classified ALS data was used to create simple building models and a triangulated Digital Elevation Model (DEM) for the ground. The laser-based DEM was textured using the orthoimages.

It is essential to ensure the common coordinate frame for multi-source data sets [38]. The terrestrial data set was manually registered with the models generated from airborne data. Rhinoceros 4 software was applied, together with the Pointools Plugin for Rhino, in visualizing the TLS point clouds and the models generated from ALS data. The walls of buildings and the ground surface were the main features that were examined during the registration. Because of the low point density of the airborne data, the buildings included some inaccuracies. However, the terrestrial data were used to improve the accuracy of the building models. In this process, the building models were manually edited to visually match the TLS point cloud. For example, the heights of the building models were adjusted to correlate with the TLS data. In a similar manner, the wall surfaces were moved to match the TLS data more accurately.

In order to increase the photorealistic appearance, the final visualizations were produced from textured building models, using Blender software. The textures of roofs were extracted from aerial orthoimages. For the walls, terrestrial images with the size of $1024 \times 1024$ pixels were applied. Texture images were rectified to the wall planes by projective transformation [39].

There were also some trees in courtyards. The locations of the trees in the model were extracted from the laser point cloud. Scaled and rotated tree objects were placed in those locations. The tree object used was a typical rendering tree, consisting of 39 triangle faces textured with two texture images (Figure 1). Only one type of tree

Table 1. Faro focus 3D TLS system specifications.

\begin{tabular}{cc} 
Specification & Faro focus 3D \\
Field of view & $360^{\circ} \times 305^{\circ}$ \\
Measurement range & $120 \mathrm{~m}$ \\
Max. speed (points per sec) & 976,000 \\
Beam diameter at the exit aperture & $3 \mathrm{~mm}$ \\
Beam divergence & $0.22 \mathrm{mrad}$ \\
Distance measurement accuracy at $25 \mathrm{~m}$ & $\pm 2 \mathrm{~mm}$ \\
Max resolution hor. $\times$ ver. & $0.009^{\circ} \times 0.009^{\circ}$ \\
Max points 360 hor. $\times$ ver. & $40,960 \times 40,960$ \\
Laser wavelength & $905 \mathrm{~nm}$ \\
Laser power & $20 \mathrm{~mW}$ \\
\hline
\end{tabular}




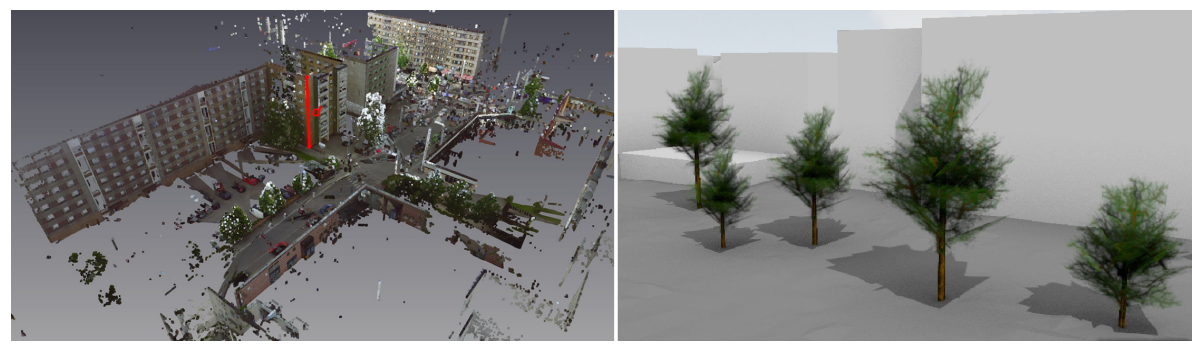

Figure 1. Co-registered TLS point clouds, and the tree model used in rendering. The feature (d) marked with a red line is $23.2 \mathrm{~m}$ high.

was used, because the variation of tree species in the test area was limited. In order to reduce the effect of the similar appearance of trees, the tree objects were rotated randomly around the height axis, and scaled according to the sizes of the actual trees.

\subsection{Visualizing the Infill Development}

A 3D model of the infill building was created manually. Laser scanning data and the layout plan of the area were utilized to define the correct location and size of the new building. In order to simulate high and low infill building alternatives, two models with a different number of floors were created. The height of the buildings was defined by calculation, based on a floor height of $2.7 \mathrm{~m}$.

The textures for the models of infill buildings were created by combining a set of images depicting contemporary building facades that were separately photographed. For the two models, different textures were created. The textures were created by forming a mosaic of geometrically corrected images of existing buildings. In Figure 2 we can see some of the photos used, and a final texture image made by combining these photos.

After the 3D models were ready, the customized visualizations were created by rendering the infill development model and the environment model. For each residential floor of the adjacent building, three locations on the floor were used to create visualizations of the infill building. In total, there were 18 camera positions. For each position, three images were rendered, depicting the scene from the window in three scenarios: the current situation, with a new six-story building, and with a new four-story building. In total, 54 images were rendered.

\subsection{Indicative Interviews-Sample, Data Collection and Analysis}

In order to recruit interviewees, invitations to participate in the study were delivered to all apartments. The participants of the study were limited to the shareholders (as decision makers) of the selected housing company, and thus, tenants were excluded. The reason to exclude tenants was based on the fact that Finnish legislation related to housing companies acknowledges only shareholders' right to participate the decision making concerning the infill development in the area governed by the housing company.

Shareholders were asked to fill in a short questionnaire regarding their views on the potential infill development within their housing company and neighborhood, and their willingness to participate in an interview. Altogether six responses were received, out of which one was willing to fill in the questionnaire but declined the interview. In order to increase the response rate, another recruitment round was performed. However, no additional responses were received.

Four interviews were carried out during fall 2013 and spring 2014 (one of the potential interviewees could not be reached, despite multiple attempts). The interviewees were the chairperson of the housing company's board, the housing manager (who were both also shareholders), and two regular owner-occupiers. In total, the interviewees constituted over $10 \%$ of the shareholders.

As a warm-up for the interview, the interviewees were requested to describe the housing company in which they were living. After that, they were asked if they knew whether the housing company was currently planning an infill development and, if so, what was their opinion on the matter. This part of the interview served as introduction to the topic.

This was followed by the presentation of a layout drawing illustrating the potential infill development for the housing company. The interviewees were asked to describe their perceptions related to the layout drawing and infill development. In the final part of the interview, the customized visualizations and animations were presented 

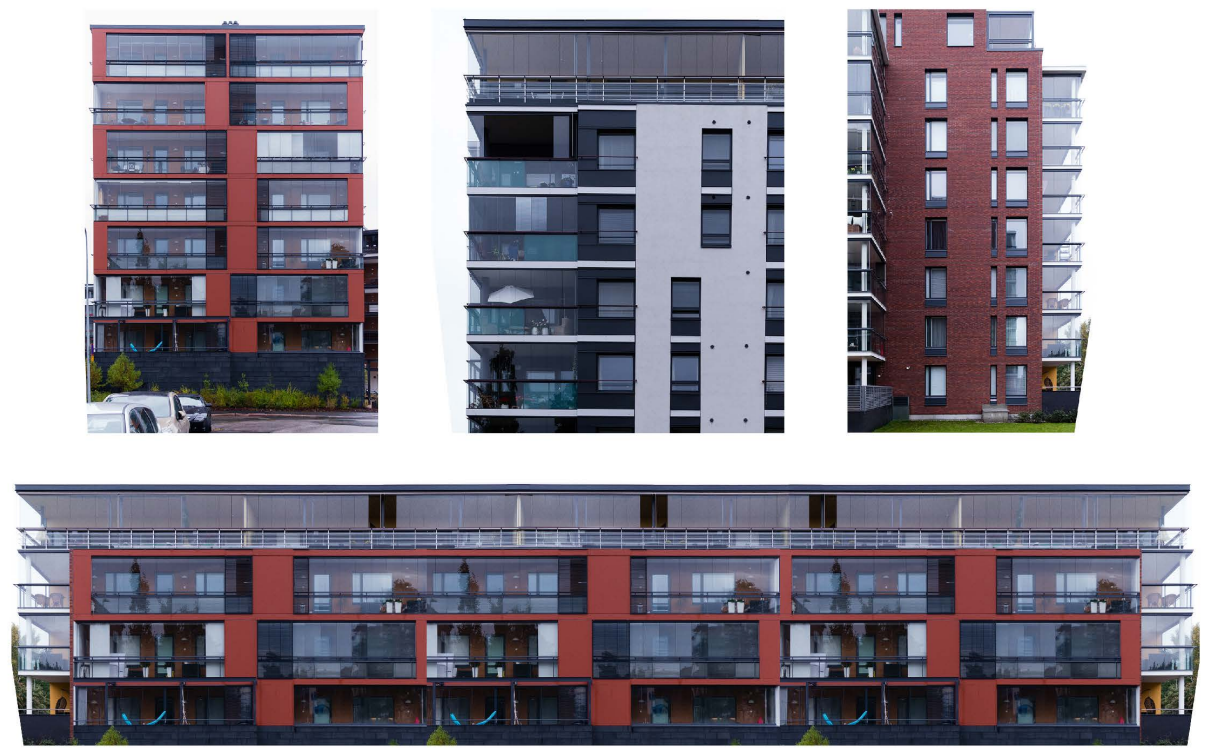

Figure 2. Three photos of existing contemporary buildings (top) and a synthetic texture image made by combining them (bottom).

and the participants' views on those were discussed. This part was intended to reveal the local stakeholders' perceptions of the customized visualizations. The interviews lasted between 45 - 90 min and were held in the interviewees' homes or in a nearby lunch restaurant. The interviews were tape-recorded and transcribed. The interviewees received an incentive (a bag of groceries worth approximately 25 euros) for participating the study.

The data analysis followed the logic of Grounded Theory, in which data-driven categories of the studied phenomenon are created [40] [41]. This approach was chosen due to the lack of previous literature of the studied topic. In practice, the data was analyzed in the following manner. Firstly, the transcribed interviews were read several times. This was done to form an initial understanding of the respondents' views on the customized visualizations and their utility. In the second step of the analysis, abstract categories of the added value generated by customized visualizations from the interviewees' perspective were developed. These categories were based on the single observations from the interviews. In the final phase, the categories were discussed within the research group in order to find any ambiguities in the interpretations.

\section{Materials and Methods}

\subsection{Customized Visualizations of Alternative Infill Development Scenarios}

Based on the 3D model of the existing environment, and the virtual model of the infill development, it was possible to create customized visualizations. The visualizations help comprehension of the influence of infill development from different locations in the adjacent building. With these visualizations, it was possible for individual interviewees to see the effects of the proposed infill development from their own apartment. Some of the apartment specific visualizations are shown in Figures 3-5. The rendered images were printed in A3 size, and arranged in a folder to help locate the correct images for the interviews. In addition, fly-through and streetlevel animations were created. The videos were also rendered with three setups, showing the current state, with a new six-story building, and with a new four-story building (Figure 6).

\subsection{The Findings of the Interviews}

The interviews indicate that customized visualizations can help stakeholders conceptualize, plan, and manage an infill development at the early phase of a project. Based on the analysis of the interviews, three main categories were developed to illustrate how the stakeholders perceived the customized visualizations and animations. The first category relates to the planning of the infill development, the second to the perceived impact of the infill development, and the third to the management of the infill development project. 


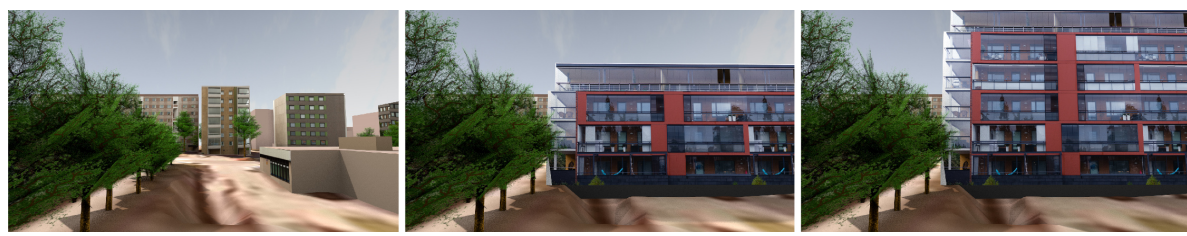

Figure 3. Rendered images showing the view from the window of the lowest residential floor of the adjacent building in the current situation (left), with a new four-story building (middle), and with a new six-story building (right).
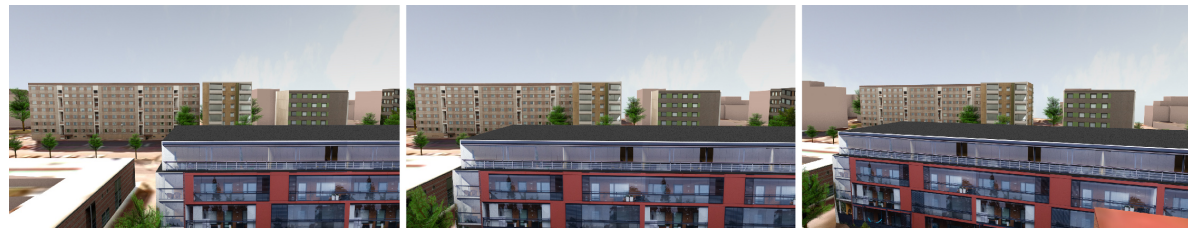

Figure 4. Rendered images showing the view from three different windows of the top floor.
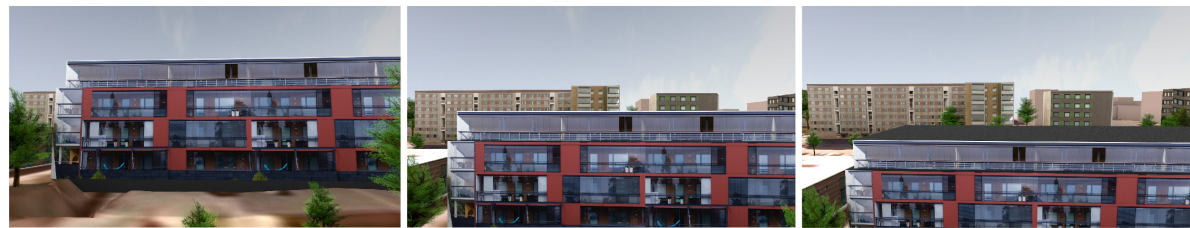

Figure 5. Rendered images showing the view with a new four-story building from the lowest residential floor (left), the middle floor (middle), and the top floor (right).
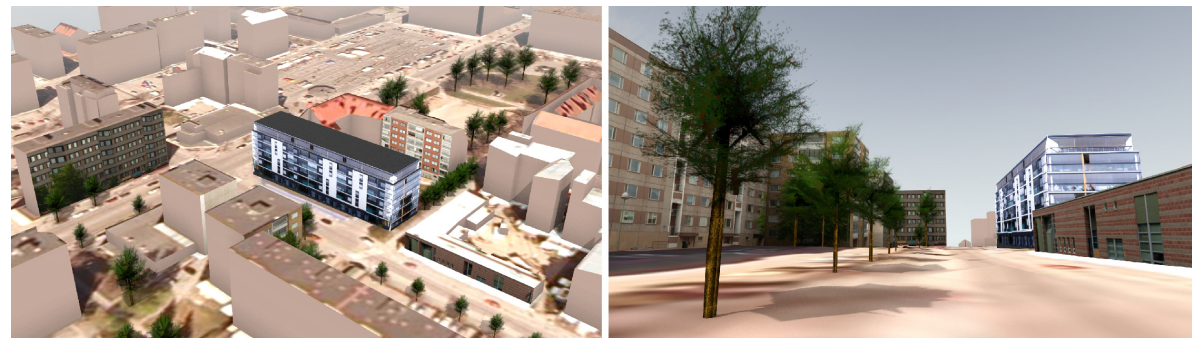

Figure 6. Still images from animations showing the area from an aerial view (left) and a pedestrian view (right).

\subsubsection{Category 1: Planning}

For the stakeholders, the customized visualizations and animations provided the possibility to contemplate the visual design of the new building and its location on the plot. Prior to seeing the customized visualizations, most of the interviewees were worried that the size of the plot was too small for a new building, even when the suggested infill development was to demolish an existing low-rise building and replace it with an apartment house. Seeing the models strengthened their worries of the cramped plot. Some interviewees started to envision a better location for the new building.

"Yes. Oh my! The house [the infill building] is beautiful. It looks like a piece of candy. I have nothing against it but I criticize our house and our small plot. And I can’t help it. And there is the taller [building] then. Oh dear!” (Resident 1)

"It is a terrible chunk to [come] here. It is a terrible chunk. As these buildings are so close to each other here. They are completely side by side.” (The chairperson)

“... but it is in the wrong place. If it would be even ten meters this way, there would be some kind of breathing hole. I mean between this [apartment] house and the other one [the infill building]”. (Resident 1)

After seeing the customized visualizations, some of the interviewees were able to more thoroughly discuss the use of the plot. They mentioned road lines, emergency routes, the routes for collecting the rubbish, and the sig- 
nificance of the trees. For the stakeholders, the customized visualizations provided a chance to better conceptualize the planning of the infill development.

\subsubsection{Category 2: Impact}

For the interviewees, the customized visualizations assisted in conceptualizing the impact of the infill development on their surroundings. Firstly, the interviewees understood the mass of the new building better after studying the visualizations. This was particularly clear when the interviewees saw the new building from the perspective of their own apartment windows or balcony. This was found out by comparing the perceived effects of the infill development on different floors. Overall, the six-floor building caused more suspicion than the four-floor building. This was due to the mass of the building and the loss of views and/or the living convenience.

Interviewer: "Is there a difference between four and six floors?"

Interviewee: "Well, yes a little. The yard is even more like some canyon [with the six-story building]" (Resident 2)

“...there are walls around [unfinished thoughts]. Sure, there are [walls] here as well, but here you have more air space than there [compares the four- and six-story buildings]. It is completely blocked. It does not look very good." (Resident 2)

...

Interviewee (The chairperson commenting on the proposed six-floor apartment.): "Even worse.”

Interviewer: "What makes it even worse?"

Interviewee: "It blocks our yard. ... Although we are in the middle of the city, you cannot take away the living convenience of people."

$\cdots$

Two of the interviewees said that they would not have needed the customized visualizations to comprehend the negative impact of the tall infill building. Nevertheless, the visualizations seemed to enhance their negative views on the infill development and its impact.

Secondly, some of the interviewees were able to better comprehend the unequal position of the residents living in the different parts of the existing apartment building in regard to the infill building. The interviewees were able to browse through folder of customized visualizations from every floor of their building. They were concerned about the residents in the lowest floors and those of one end of the existing building, as the new building would block their views the most.

“... it is quite blocked then. Most of all for them; for those who are living there.” (Resident 2, referring to the people living at the opposite end of the existing apartment house, where the view was more blocked)

Thirdly, with the customized visualizations, the interviewees were able to recognize the streets and buildings of the neighborhood. This was particularly clear when compared to the illustrations of the infill development they had seen earlier in the newspapers or at the infill development briefing held by the city. All the interviewees were very critical of the infill development illustrations they had seen earlier.

“It is very clear here. I recognize very clearly what is proposed through all these pictures. I don't have to ask 'What on earth is that?' and 'Where is that street?' ... I saw it very clearly and recognized all the buildings in the neighborhood. This is a thousand times better than the white shoe boxes...” (Resident 1, comparing the visualizations to the illustrations presented at the city briefing)

Fourthly, the loss of trees, green areas and urban fauna due to the infill development caused concern to one interviewee after seeing the 3D models.

\subsubsection{Category 3: Management}

The possibility of an infill development had been discussed earlier in a general assembly of the housing company, and the management had met the representatives of the city and developers. However, no plans for the infill development existed, and the stance of the general assembly towards the infill development on the plot of the housing company was critical. The housing manager considered the customized visualizations essential for planning the infill development. The visualizations would enable both the residents and the management to conceptualize the infill development, assist planning, and make the entire infill development process easier. The housing manager emphasized that tools like customized visualizations had been missing completely from the infill development discussions. The visualizations would be useful in his job. Also, the chairperson saw the cus- 
tomized visualizations as useful tools, especially for residents with no expertise in construction.

"Yes. And this corner-a sizeable building [to be put] there and height; that kind of thing will bring that space. ... And when we get this garage as a storage space and more [storage space will] come here. The garage of the new building would come to this entity and the drive-in here. [With this kind of plan] It will be approved [by residents]. The city has only presented raunchy illustrations in the newspaper.” (The housing manager brainstorms using the 3D models)

"If we would use this, it would be the lower option [four-story building]. But we need this kind of tool. ... Showing how it looks like. And in the same way, if there was not this kind of long mass on the front-so it comes here, to the corner, rises up like this [explains by using the visualizations]. A person can see it will be like this, and this manner of representation is more illustrative." (The housing manager)

"It makes it easier to conceptualize- this type of working takes the process ahead." (The housing manager)

According to the housing manager, the use of customized visualizations in the early phase of planning the infill development could bring more control to the residents of housing companies and adds to the possibilities of resident-driven planning. This was considered particularly important in relation to the city-led general level planning for the infill development in Tammela. Both the housing manager and the chairperson were critical of the infill development push made by the city, although they understood the city's need for housing intensification.

"Infrastructure costs are of course probably the most crucial issue dictating why this needs to be intensified. And that is why the city has made these original plans. They [city representatives] say that if they hadn't made any of these illustrations - the issue wouldn't proceed anywhere. But, on the contrary, they [referring to the city's infill development illustrations and plans] caused the opposition: 'No such colossus here!'” (The chairperson)

Additionally, many issues mentioned under previous categories would provide valuable input to the management of the infill development process. For example, the decrease of the living convenience and the unequal position of the residents living in the different parts of the apartment house building would have to be considered.

\section{Discussion}

The first aim of the study was to test the feasibility of producing customized visualization of infill development for the local stakeholders. The final customized visualizations illustrate two alternative infill development buildings from different locations in the adjacent building. As the described visualization method relies on 3D models as the source material for producing the visualizations, the tasks and costs of utilizing the method can be divided into costs of modeling and costs of visualization. Both 3D models depicting the proposed infill buildings and their surroundings have to be available before the visualizations can be made. In the presented case, a measuring campaign was required to produce the model of the urban environment. The visualizations were made from a 3D model based on combining ALS and TLS data.

As a terrestrial laser scanner was used in measuring, the cost of the measuring device has to be also taken into account. A one-day measuring campaign was required for acquiring the data, after which several working days were required for modeling. The process of modeling from TLS data has been reported to be very time taking by other authors as well [42]. In total, measuring and modeling the environment was the most time consuming and costly part of the visualization process.

After the 3D model of the environment was available, models depicting the infill development scenarios were made. Each scenario of infill development requires separate design model, which leads to manual work. Usually, 3D design models are rendered as 2D illustrations for easy distribution and visualization. For both of these steps a large amount of tools are available, both commercial (e.g. [43]) and open source (e.g. [44]).

In the future, we can assume that the development of measuring technologies continues, making the measuring instruments more efficient and affordable. For larger areas mobile mapping systems would be the most efficient method for collecting detailed 3D data [45]. In addition, it is possible that detailed city models, as illustrated by Zhu et al. [46], become readily available. For example, a 3D city model of Rotterdam [47] containing textured building models can be downloaded as open data in City GML format [48]. There are also projects for voluntarily producing 3D maps of large areas (e.g. [49]). As such models emerge, it may become possible to produce these customized visualizations without the measuring work, significantly reducing the costs of producing presented visualizations. 
When compared with the model presented in [46] or [47] our model is clearly more limited in area, only representing a small set of buildings, instead of a city part, or an entire urban area. In addition, only segments of building facades have been textured in our model, whereas in [46] all buildings have been textured. As such our model cannot be used for representing changes in the other parts of the Tammela area, but only in the few particular, measured blocks. This also has an effect on the usable measuring techniques. For modeling a set of few buildings, it is feasible to use TLS. For larger areas, more efficient measuring methods, such as ALS or MLS are required. The detail level of buildings is comparable, as all three mentioned models contain simplified building geometries with photo textures. In our model, the vegetation is represented as simple models of major trees, which is missing from [46]. If we compare the detail level of our model to the Levels-of-Detail used in CityGML [48], we can see that our model is LoD2, or slightly above that in the most accurate sections. The parts of the model that have been produced solely from ALS data are closer to LoD1.

In addition to the rendered images and animations used in this study, there are alternative methods of visualizing digital 3D models. Game engines can be utilized to produce multimodal simulations, such as that presented by Manyoky et al. [22]. AR applications can be used for visualizing virtual objects in the existing physical environment. However, for immersive and interactive applications, more accurate models are also required, increasing the costs of using such tools [50]. In our work, the stakeholders found the images and animations very useful. In this sense, static visualizations are a feasible alternative.

The second aim of the study was to explore the stakeholders' attitudes and perceptions towards these customized visualizations by indicative interviews. With the visualizations, stakeholders (here, owner-occupiers and the management of a housing company) were able to see how the small-scale infill development would change the surroundings of their apartments.

Considering the NIMBY attitudes and resistance towards infill development, residents may hold strong senses on the way of living in their neighborhood, and see the infill development as chaotic and conflicting [10]. The customized visualizations could have an important role in alleviating the local stakeholders' NIMBY-attitude. Schively states various means to respond to NIMBY-concerns [51]. Two of those are especially relevant from visualizations perspective, namely communicating about impacts and empowering affected parties. With the visualizations, the residents can better understand the potential impact of infill development on their surroundings. In addition, different options for infill development can be communicated to the residents. This could help evoke a sense of control on changes and enable the residents to communicate their concerns in a more concrete manner to the relevant stakeholders. Indeed, the results showed that the residents were able to provide rich descriptions of the infill development impacts. The perceived effects were linked to a loss of open (air) space and, consequently, a decrease in the living convenience. Both of these were more acute with the higher (the six-story) infill building. Thus, the visualizations could offer an effective tool to tailor the infill development plans in a manner that the impact is acceptable to the residents and at the same time restrain NIMBY-outlooks.

Residents often place distrust in the stakeholders planning different developments (e.g. [14]) which can lead to NIMBY-considerations [51] [52]. Empowerment of residents is seen as one mean to reduce the distrust [51] and can include, for example, utilization of residents' own experts in infill development planning process or other means to evaluate the potential risks [51]. Visualizations could be useful in such process. For instance, some professional (but neutral) third party set by a government or hired by the residents could utilize visualizations to collect residents' views on the planned infill development and suggestions to alter the plans. This type of procedure would integrate the residents to the planning process and provide them a sense of empowerment on developments in their surroundings. At the same time, the residents' suggestion would be more concrete in nature, translated by the third party experts in a form understandable to other stakeholders and thus easier to take into account in further planning process.

Finally, our aim was to assess the utility of customized visualizations in infill development projects. The visualizations offered a possibility to study the visual impact of the infill building from three different positions on each floor of the adjacent building. When assessing the views from apartments, residents of different floors were found to be in unequal positions. For example, the new four-story building barely reached the horizon when seen from the top floor of the adjacent building but completely obscured the view of the people living on the first residential floor. For their apartments, such a project would have had a huge impact, as the interviewees noted. This needs to be taken into account when considering the rights of individual owners and the distribution of the benefits and disadvantages of an infill development.

In addition, the customized visualizations helped the stakeholders to give preconditions for the infill devel- 
opment project, such as the disposition and the number of floors of the infill building and the use of the plot. Customized visualizations can be shown and discussed in joint meetings and could successfully be a part of a participatory decision-making processes. They possess great communication potential by visualizing different scenarios [14].

Detailed visualizations reduce the possibility of misunderstanding and ease the orientation of a viewer [53]. From the textured visualization of the new building, the interviewees were also able to distinguish the amount of floors, and its use (residential, commercial), unlike the "white slab visualizations" they had seen earlier in a city briefing and in the local media. However, the use of detailed visualizations is not problem free [18]. As hypothetical details are added to visualizations, the users may start giving feedback on them, instead of on the overall plan. In this study, we chose to present the new building with a realistic image texture based on contemporary apartment buildings. The interviewees strongly criticized the disposition of the infill building and pinpointed other shortcomings of the infill development, and thus seemed to be able to get past the detailed appearance of the building. It also has to be noted, that in the present case the infill development scenarios introduced a major change to the environment. Such a large change is easily observable even in simple visualizations. If the changes to the environment are to be less drastic, e.g. a renovation and minor modifications of a nearby building, it may become more difficult to present them with simplified models. In a similar manner, as the vegetation was represented in a simplified manner, it might be difficult to illustrate changes related to urban vegetation with such models.

The management of the infill development project in the housing company benefits from the customized visualizations. Visualizations provide a new tool to help understand and give input to the infill development on the plot of the housing company. The use of customized visualizations could enable resident-driven infill development as opposed to the traditional, top-down planning (see, [14]) as it enables the residents’ participation from the very beginning.

In the future we can expect that improving virtual models enable a more efficient production of visualizations, game engine mediated, interactive visualizations [46] and possibly even physical presentation models [54]. Virtual models may also become a platform for social activities, combining the physical and virtual worlds [55].

\section{Conclusions}

In this study, customized visualizations of two different infill development scenarios were made, showing the new buildings from each floor of a neighboring residential multi-story building. The visualizations were made using 3D models of the new buildings and the existing environment. These floor-by-floor visualizations were used together with animations in indicative interviews of local stakeholders. The interviewees were owneroccupiers, a housing manager and a chairperson of a housing company's board.

The findings indicate that the customized visualizations work as an instrument helping the stakeholders conceptualize the impact of infill development. They can also be used to plan and manage an infill development at an early phase of the project. Additionally, they can be seen as a tool for a more resident-driven approach to intensifying housing (when compared to the traditional, top-down planning) due to their communication, planning, and participatory potential.

In the Tammela area and many other older neighborhoods in Finland, housing companies are the main landowners. Thus, they are the main stakeholders in initiating infill developments and have a key role in decision making. For them, infill development is a viable way to finance major repairs to buildings. Tools, like customized visualizations, will most likely be welcomed by the housing companies considering or planning an infill development. Qualitative research with more interviews would enable a deeper understanding of this topic.

Currently, the technology and know-how required for measuring and modeling the existing environment increases the costs of producing the visualizations presented. As the technology is developed further, these costs can be expected to reduce. If high quality city models continue to emerge, it is even possible that the measuring and modeling work becomes mostly unnecessary for producing the presented visualizations. As producing simple 3D models of planned buildings, and using them for visualization is already quite common, we can assume that with the availability of city models the presented use of visualizations could become more of a standard practice in infill development in the future.

Possible topics of further research include the development of customized visualizations into a scenario-based tool for participatory planning, offering more alternatives for stakeholders to discuss. In addition, the use of 
customized visualizations in an ongoing infill development project would enable the use of detailed models in the decision making of construction projects.

\section{Acknowledgements}

The ALS data was obtained from the open data service of the NLS. This research project was supported by the Academy of Finland, the Centre of Excellence in Laser Scanning Research (CoE-LaSR) (272195), Research on Resident-Driven Infill Development Possibilities-Case Study in Urban Areas in Finland (REPSU) (255390), The Finnish Funding Agency for Innovation, “A healthy building”-project (40250/14) and the Aalto Energy Efficiency Research Programme (Light Energy—Efficient and Safe Traffic Environments project), the EUE project (2141226), and the Aalto University doctoral program.

\section{References}

[1] Burton, E., Jenks, M. and Williams, K. (2003) The Compact City: A Sustainable Urban Form? Routledge, London.

[2] Curtis, C., Renne, J.L. and Bertolini, L. (2009) Transit Oriented Development: Making It Happen. Ashgate Publishing, Ltd., Farnham.

[3] Newton, P. and Glackin, S. (2014) Understanding Infill: Towards New Policy and Practice for Urban Regeneration in the Established Suburbs of Australia's Cities. Urban Policy and Research, 32, 1-23. http://dx.doi.org/10.1080/08111146.2013.877389

[4] Williams, E. (2007) Innovative Land Use Planning Techniques: A Handbook for Sustainable Development.

[5] Newton, P. (2013) Regenerating Cities: Technological and Design Innovation for Australian Suburbs. Building Research \& Information, 41, 575-588. http://dx.doi.org/10.1080/09613218.2013.803921

[6] Danielsen, K., Lang, R. and Fulton, W. (1999) Retracting Suburbia: Smart Growth and the Future of Housing. Housing Policy Debate, 10, 513-540. http://dx.doi.org/10.1080/10511482.1999.9521341

[7] Steinacker, A. (2003) Infill Development and Affordable Housing. Urban Affairs Review, 38, 492-509. http://dx.doi.org/10.1177/1078087402250357

[8] OECD (2012) Compact City Policies: A Comparative Assessment. OECD Green Growth Studies. OECD Publishing.

[9] Farris, J.T. (2001) The Barriers to Using Urban Infill Development to Achieve Smart Growth. Housing Policy Debate, 12, 1-30. http://dx.doi.org/10.1080/10511482.2001.9521395

[10] Vallance, S., Perkins, H. and Moore, K. (2005) The Results of Making a City More Compact: Neighbours’ Interpretation of Urban Infill. Environment and Planning B, 32, 715. http://dx.doi.org/10.1068/b31157

[11] Wiley, K. (2007) An Exploration of Suburban Infill. Resources for the Future, College Park. http://www.rff.org/rff/events/upload/30215_1.pdf

[12] Lang, R.E., Hughes, J.W. and Danielsen, K.A. (1997) Targeting the Suburban Urbanites: Marketing Central-City Housing. Housing Policy Debate, 8, 437-470. http://dx.doi.org/10.1080/10511482.1997.9521260

[13] von Haaren, C., Warren-Kretzschmar, B., Milos, C. and Werthmann, C. (2014) Opportunities for Design Approaches in Landscape Planning. Landscape and Urban Planning, 130, 159-170. http://dx.doi.org/10.1016/j.landurbplan.2014.06.012

[14] Tress, B. and Tress, G. (2003) Scenario Visualization for Participatory Landscape Planning—A Study from Denmark. Landscape and Urban Planning, 64, 161-178. http://dx.doi.org/10.1016/S0169-2046(02)00219-0

[15] Lewis, J.L. and Sheppard, S.R. (2006) Culture and Communication: Can Landscape Visualization Improve Forest Management Consultation with Indigenous Communities? Landscape and Urban Planning, 77, 291-313. http://dx.doi.org/10.1016/j.landurbplan.2005.04.004

[16] Wagner, I., Basile, M., Ehrenstrasser, L., Maquil, V., Terrin, J.-J. and Wagner, M. (2009) Supporting Community Engagement in the City: Urban Planning in the MR Tent. Proceedings of the 4th International Conference on Communities and Technologies, University Park, 25-27 June 2009, 185-194. http://dx.doi.org/10.1145/1556460.1556488

[17] Priess, J.A. and Hauck, J. (2014) Integrative Scenario Development. Ecology \& Society, 19, 12. http://dx.doi.org/10.5751/ES-06168-190112

[18] Oksman, V., Väätänen, A. and Ylikauppila, M. (2014) Co-Creation of Sustainable Smart Cities. Proceedings of the 8th International Conference on Mobile Ubiquitous Computing, Systems, Services and Technologies, Rome, 24-28 August 2014, 189-195.

[19] Day, A. (2002) Urban Visualization and Public Inquiries: The Case of the Heron Tower, London. Architectural Research Quarterly, 6, 363-372. http://dx.doi.org/10.1017/S135913550300188X 
[20] van Schaik, P. (2010) Using Interactive 3-D Visualization for Public Consultation. Interacting with Computers, 22, 556-568. http://dx.doi.org/10.1016/j.intcom.2010.06.002

[21] Yan, W., Culp, C. and Graf, R. (2011) Integrating BIM and Gaming for Real-Time Interactive Architectural Visualization. Automation in Construction, 20, 446-458. http://dx.doi.org/10.1016/j.autcon.2010.11.013

[22] Manyoky, M., Wissen Hayek, U., Heutschi, K., Pieren, R. and Grêt-Regamey, A. (2014) Developing a GIS-Based Visual-Acoustic 3D Simulation for Wind Farm Assessment. ISPRS International Journal of Geo-Information, 3, 29-48. http://dx.doi.org/10.3390/ijgi3010029

[23] Mól, A.C.A., Jorge, C.A.F. and Couto, P.M. (2008) Using a Game Engine for VR Simulations in Evacuation Planning. Computer Graphics and Applications, 28, 6-12. http://dx.doi.org/10.1109/MCG.2008.61

[24] Oculus Rift, Next-Gen Virtual Reality. http://www.oculusvr.com/rift/

[25] Behzadan, A.H. and Kamat, V.R. (2005) Visualization of Construction Graphics in Outdoor Augmented Reality. Proceedings of the 37th Conference on Winter Simulation, Orlando, 4-7 December 2005, 1914-1920. http://dx.doi.org/10.1109/WSC.2005.1574469

[26] Cirulis, A. and Brigmanis, K.B. (2013) 3D Outdoor Augmented Reality for Architecture and Urban Planning. Procedia Computer Science, 25, 71-79. http://dx.doi.org/10.1016/j.procs.2013.11.009

[27] Remondino, F., Spera, M.G., Nocerino, E., Menna, F. and Nex, F. (2014) State of the Art in High Density Image Matching. The Photogrammetric Record, 29, 144-166. http://dx.doi.org/10.1111/phor.12063

[28] Vosselman, G. and Maas, H.-G. (2010) Airborne and Terrestrial Laser Scanning. Whittles Publishing, Caithes, 336.

[29] Kaartinen, H., Hyyppä, J., Kukko, A., Jaakkola, A. and Hyyppä, H. (2012) Benchmarking the Performance of Mobile Laser Scanning Systems Using a Permanent Test Field. Sensors, 12, 12814-12835. http://dx.doi.org/10.3390/s120912814

[30] Mangioni, V., Viitanen, K., Falkenbach, H. and Sipilä, T. (2012) Three Dimensional Property Rights and Reassembly: Cases of Sydney and Helsinki. Proceedings of FIG Working Week, Rome, 6-10 May 2012.

[31] Pennanen, K., Tiilikainen, A. and Viitanen, K. (2013) Exploring Ways to Successful Resident-Driven Infill Development: Lessons Learned from Two Cases in Helsinki Area. Proceedings of SB13 Oulu on Sustainable Procurement in Urban Regeneration and Renovation, Oulu, 21-25 May 2013.

[32] Puustinen, T. and Lysnar, P. (2014) Time for Intensity? Governance and Decision-Making in Relation to Major Repairs in Multi-Owned Residential Buildings in Finland and New Zealand. Proceedings of PRRES, Lincoln, 20-22 January 2014.

[33] Falkenbach, H. and Nuuja, K. (2007) Flat Ownership and Registration in Europe: An Overview. Proceedings of FIG Working Week, Hong Kong SAR, 13-17 May 2007.

[34] Tammelan yleissuunnitelma (General Layout Plan of the Tammela Area), City of Tampere, Tampere, 2012.

[35] Laine, M. and Leino, H. (2013) Strategista suunnittelua vai sirpaleista sijoittelua-Täydennysrakentamisen mahdollisuudet kaupunkikeskustassa (Strategic Planning or Fragmented Disposition-The Possibilities of Housing Densification in a City Center). Kunnallistieteellinen Aikakauskirja, 4, 407-422.

[36] Fraser, C.S. (1997) Digital Camera Self-Calibration. ISPRS Journal of Photogrammetry and Remote Sensing, 52, 149159. http://dx.doi.org/10.1016/S0924-2716(97)00005-1

[37] Axelsson, P. (2000) DEM Generation from Laser Scanner Data Using Adaptive TIN Models. International Archives of Photogrammetry and Remote Sensing, 33, 111-118.

[38] Cheng, L., Tong, L., Li, M. and Liu, Y. (2013) Semi-Automatic Registration of Airborne and Terrestrial Laser Scanning Data Using Building Corner Matching with Boundaries as Reliability Check. Remote Sensing, 5, 6260-6283. http://dx.doi.org/10.3390/rs5126260

[39] Jagannathan, L. and Jawahar, C.V. (2005) Perspective Correction Methods for Camera-Based Document Analysis. Proceedings of the First International Workshop on Camera-Based Document Analysis and Recognition (CBDAR), Seoul, 29 August-1 September 2005, 148-154.

[40] Glaser, B.G. and Strauss, A. (1967) The Discovery of Grounded Theory, Strategies for Qualitative Research. Aldine Publishing Company, Chicago.

[41] Strauss, A. and Corbin, J. (1990) Basics of Qualitative Research: Grounded Theory Procedures and Techniques. Sage, Newbury Park.

[42] Beraldin, J.A., Picard, M., El-Hakim, S.F., Godin, G., Valzano, V., Bandiera, A. and Latouche, C. (2002) Virtualizing a Byzantine Crypt by Combining High-Resolution Textures with Laser Scanner 3D Data. Proceedings of VSMM 2002, Gyeongju, 25-27 September 2002, 3-14.

[43] SketchUp. http://www.sketchup.com/ 
[44] Blender. http://www.blender.org/

[45] Kukko, A., Kaartinen, H., Hyyppä, J. and Chen, Y. (2012) Multiplatform Mobile Laser Scanning: Usability and Performance. Sensors, 12, 11712-11733. http://dx.doi.org/10.3390/s120911712

[46] Zhu, L., Hyyppä, J., Kukko, A., Kaartinen, H. and Chen, R. (2011) Photorealistic Building Reconstruction from Mobile Laser Scanning Data. Remote Sensing, 3, 1406-1426. http://dx.doi.org/10.3390/rs3071406

[47] Rotterdam 3d. http://www.rotterdam.nl/rotterdam_3d

[48] Gröger, G. and Plümer, L. (2012) CityGML-Interoperable Semantic 3D City Models. ISPRS Journal of Photogrammetry and Remote Sensing, 71, 12-33. http://dx.doi.org/10.1016/j.isprsjprs.2012.04.004

[49] OSM-3D Globe, Information. http://www.osm-3d.org/informationen.en.htm

[50] Wergles, N. and Muhar, A. (2009) The Role of Computer Visualization in the Communication of Urban Design-A Comparison of Viewer Responses to Visualizations versus On-Site Visits. Landscape and Urban Planning, 91, 171182. http://dx.doi.org/10.1016/j.landurbplan.2008.12.010

[51] Schively, C. (2007) Understanding the NIMBY and LULU Phenomena: Reassessing Our Knowledge Base and Informing Future Research. Journal of Planning Literature, 21, 255-266. http://dx.doi.org/10.1177/0885412206295845

[52] Smith, E.R.A.N. and Marquez, M. (2000) The Other Side of the NIMBY Syndrome. Society \& Natural Resources, 13, 273-280. http://dx.doi.org/10.1080/089419200279108

[53] Nurminen, A. and Oulasvirta, A. (2008) Designing Interactions for Navigation in 3D Mobile Maps. In: Meng, L.Q., Zipf, A. and Winter, S., Eds., Map-Based Mobile Services, Springer Berlin Heidelberg, Berlin, 198-227. http://dx.doi.org/10.1007/978-3-540-37110-6_10

[54] Virtanen, J.P., Hyyppä, H., Kurkela, M., Vaaja, M., Alho, P. and Hyyppä, J. (2014) Rapid Prototyping-A Tool for Presenting 3-Dimensional Digital Models Produced by Terrestrial Laser Scanning. ISPRS International Journal of Geo-Information, 3, 871-890. http://dx.doi.org/10.3390/ijgi3030871

[55] Alavesa, P., Ojala, T. and Zanni, D. (2014) Props: 3D-Game-Like Mediator for Improvisational Storytelling. Entertainment Computing, 5, 381-390. http://dx.doi.org/10.1016/j.entcom.2014.10.003 